\title{
Two-Step Concentration of Complex Water Samples for the Detection of Viruses
}

\author{
Kata Farkas ${ }^{1, * \mathbb{C}}$, James E. McDonald ${ }^{1}$, Shelagh K. Malham ${ }^{2}$ and Davey L. Jones ${ }^{1,3}$ \\ 1 School of Natural Sciences, Bangor University, Bangor LL57 2UW, UK; j.mcdonald@bangor.ac.uk (J.E.M.); \\ d.jones@bangor.ac.uk (D.L.J.) \\ 2 School of Ocean Sciences, Bangor University, Menai Bridge LL59 5AB, UK; s.mahlam@bangor.ac.uk \\ 3 UWA School of Agriculture and Environment, University of Western Australia, Crawley 6009, Australia; \\ Davey.jones@uwa.edu.au \\ * Correspondence: fkata211@gmail.com; Tel.: +44-1248-383056
}

Received: 22 August 2018; Accepted: 4 September 2018; Published: 10 September 2018

\begin{abstract}
The accurate detection and quantification of pathogenic viruses in water is essential to understand and reduce the risk of human infection. This paper describes a two-step method suitable for concentrating viruses in water and wastewater samples. The method involves a tangential flow ultrafiltration step that reduces the sample volume of 1-10 L to approximately $50 \mathrm{~mL}$, followed by secondary precipitation using polyethylene glycol 6000 , which reduces the volume to $1-4 \mathrm{~mL}$. For method validation, water samples were spiked with different concentrations of enteric viruses, and viral recovery in the concentrates exceeded $10 \%$ in all experiments. The method is suitable for water samples with high and low salinity and turbidity, allowing an accurate comparison of viral titers in a diverse range of water types. Furthermore, the method has the potential to concentrate other pathogens, e.g., bacteria or protozoa. Hence, the use of this method can improve the holistic assessment of risks associated with wastewater-contaminated environments.
\end{abstract}

Keywords: tangential flow ultrafiltration; virus precipitation; qPCR; enteric viruses; norovirus; mengovirus

\section{Introduction}

Enteric viruses (causing gastroenteritis) and other viral pathogens can be found in wastewater and in wastewater-contaminated surface and groundwater reservoirs. As the infective doses of these agents are low, concentration is needed to accurately quantify viruses in environmental waters and determine public health risks. A great variety of methods are available for water concentration for the recovery of viruses in wastewater and environmental water; however, many of these are not suitable and/or have not been validated for high volumes of water samples or different water types. The most frequently used method for primary concentration of water samples is filtration using electronegative (EN) or electropositive (EP) filters [1,2]. During EN or EP filtration, the water sample passes through the filter, while the virus particles bind to the surface of the filter due to electrostatic forces. This method has been shown to be suitable for concentrating viruses in water; however, its use may be limited to low-turbidity samples due to filter clogging during filtration. Furthermore, the use of electronegative filters requires sample preconditioning (i.e., lowering the sample $\mathrm{pH}$ ), whereas electropositive filters may not be suitable for high-salinity samples, and the elution of virus particles from the filters may be difficult as well [1].

Tangential flow ultrafiltration (TFUF) has been used for the concentration of a wide range of water samples for the detection of various pathogens [1-5]. The main advantage of the TFUF approach is that during filtration, the water flow takes place parallel to the membrane, hence membrane clogging is less frequent compared to dead-end ultrafiltration and EN and EP filtration. In general, TFUF enables 
$40-200 \times$ concentration, hence secondary concentration (filtration or precipitation) is often used to further reduce the sample volume [6-8].

This method describes an efficient, accurate, and reproducible method for concentrating enteric viruses in surface water (fresh and seawater) and wastewater (treated and untreated) samples (Figure 1). The recommended starting volumes are $10 \mathrm{~L}$ for surface water and $1 \mathrm{~L}$ for wastewater samples. The first step of the method is a TFUF step using a $100 \mathrm{kDa}$ cutoff modified polyethersulfone membrane. As described by others, the efficiency of the elution of viral particles from the membrane and the cleaning of the system is enhanced using sodium polyphosphate [4]. The final volume of the sample after TFUF is approximately $50 \mathrm{~mL}$. In order to elute viral particles attached to solid matter in the primary concentrate, samples are further mixed with beef extract and then centrifuged. Then polyethylene glycol 6000 (PEG 6000) is added to the supernatant and viral particles are precipitated. These steps are based on a method for eluting and concentrating viral particles from sediment $[9,10]$. The resulting pellet contains the viral particles that can be eluted in phosphate-buffered saline (PBS), and the solution can be stored at $-80^{\circ} \mathrm{C}$. The concentrate can be subjected to nucleic acid filtration, viral infectivity, or integrity assays.

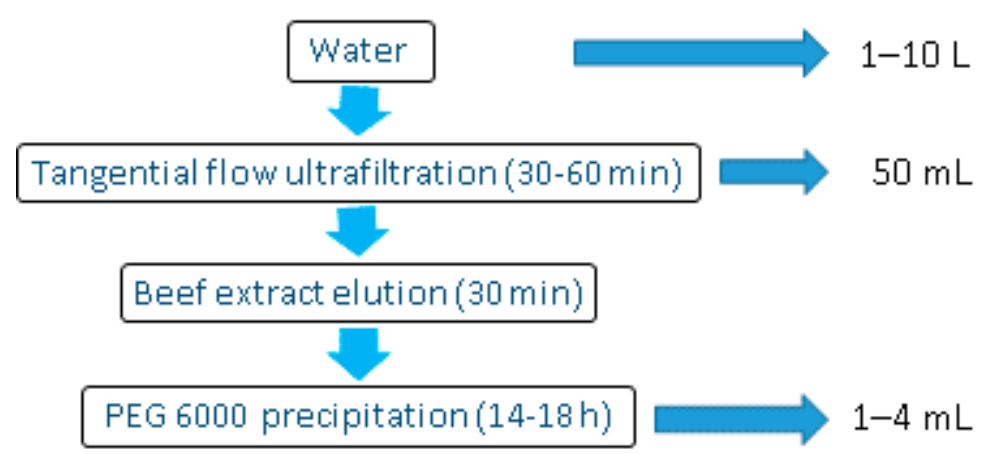

Figure 1. Stages of the tangential flow ultrafiltration-based two-step water concentration method for detection and quantification of enteric viruses in water and wastewater. PEG 600, polyethylene glycol 6000.

\section{Experimental Design}

\subsection{Materials}

- Sodium polyphosphate (NaPP)/sodium hexametaphosphate (Sigma Aldrich, St. Louis, MO, USA, Cat. no. 305553)

- $\quad$ Lab-Lemco beef extract (Oxoid, Altrincham, Cheshire, UK, Cat. no. LP0029)

- Sodium nitrate (Sigma Aldrich, Cat. no. S8170)

- Polyethylene glycol 6000 (PEG 6000) (Sigma Aldrich, Cat. no. 81255)

- $\quad$ Sodium chloride (Sigma Aldrich, Cat. no. S7653)

- Phosphate-buffered saline (PBS), pH 7.4 (Gibco PBS tablets, Life Technologies, Carlsbad, CA, USA, Cat. no. 18912-014)

- Virkon ${ }^{\circledR}$ solution (Lanxess, Cologne, Germany)

- $20 \%$ ethanol (Fisher Chemical \#E/0650/17DF, Thermo Fisher Scientific, Waltham, MA, USA)

- $\quad 0.5 \mathrm{M} \mathrm{HCl}$ and $1 \mathrm{M} \mathrm{NaOH}$ for $\mathrm{pH}$ adjustment

- Optional: $30 \mu \mathrm{L}$ mengovirus strain VMC0 solution (prepared according to ISO/TS150216-1:2013) with approximately $10^{6}$ mengovirus particles

\subsection{Equipment}

- $\mathrm{KrosFlo}^{\circledR}$ Research IIi Tangential Flow Filtration System (Spectrum Labs, Phoenix, AZ, USA, Cat. no. SYR-U20-01N) or equivalent 
- $100 \mathrm{kDa}$ mPES MiniKros ${ }^{\circledR}$ hollow fiber filter module (Spectrum Labs, USA, Cat. no. S02-E100-05-N)

- $\quad$ Silicone tubing \#17 (Spectrum Labs, USA, Cat. no. ACTU-E17-25N) or equivalent

- Centrifuge $\left(2500 \times g\right.$ and $10,000 \times g$ at $\left.4{ }^{\circ} \mathrm{C}\right)$

- Pocket-sized pH meter (Ichiro Corporation, Kotoku, Tokyo, Japan, Cat. no. S2K992) or equivalent

\section{Procedure}

\subsection{Tangential Flow Ultrafiltration (Time of Completion: 2-4 h)}

\subsubsection{System Wash}

1. Wash system (Figure 2) with $1 \mathrm{~L} 0.01 \% \mathrm{NaPP}$ solution $(0.1 \mathrm{~g} \mathrm{NaPP}$ in $1 \mathrm{~L}$ deionized water) for $5 \mathrm{~min}$ (permeate closed) then leave the membrane in the solution for 30-60 min. Wash the membrane with the NaPP solution (permeate open) until the solution has been removed.

\subsubsection{Sample Filtration}

OPTIONAL STEP Add approximately $10 \mu \mathrm{L}$ mengovirus solution to the sample and mix. Save the rest of the mengovirus sample for control measurements.

2. Filter $10 \mathrm{~L}$ of surface water or $1 \mathrm{~L}$ wastewater at $1-1.6 \mathrm{~L} / \mathrm{min}$ flow at a pressure of $5 \mathrm{psi}(0.3$ bar, $30 \mathrm{kPa}$ ) to achieve a permeate flow of $200-300 \mathrm{~mL} / \mathrm{min}$. Continue filtration until approximately $5 \mathrm{~mL}$ sample remains in the reservoir.

\subsubsection{Backwash, Recovery}

3. Set the flow to $680 \mathrm{~mL} / \mathrm{min}$ with no pressure applied and circulate the concentrate for $5 \mathrm{~min}$ with the permeate clamp closed.

4. Stop the pump, close penetrate and retentate valves.

5. Inject $20 \mathrm{~mL} 0.01 \% \mathrm{NaPP}$ solution to penetrate pressure valve. Open retentate and wash with reverse flow.

6. Collect the concentrate from the system by introducing air through the retentate port. The final volume of concentrate is approximately $50 \mathrm{~mL}$.

\subsubsection{Membrane Wash and Storage}

7. Wash membrane with $250 \mathrm{~mL}$ Virkon ${ }^{\circledR}$ solution after each sample by circulating the solution in the system (permeate closed) at low flow (400-800 mL/min). In order to reuse the membrane, immediately wash it with $150 \mathrm{~mL} 0.01 \% \mathrm{NaPP}$ solution using the setup for the Virkon wash. Repeat until solution in the process reservoir is clear. Leave the membrane in the solution for at least $10 \mathrm{~min}$ prior to reuse.

8. For long-term storage, wash the membrane with $50 \mathrm{~mL} 20 \%$ ethanol solution using the setup for the Virkon wash. Repeat until solution is clear. Disassemble the system and store membrane in $20 \%$ ethanol solution at $4{ }^{\circ} \mathrm{C}$.

\subsection{Secondary Concentration (Time of Completion: $2.5 h+$ Overnight Incubation)}

\subsubsection{Virus Elution}

9. Add beef extract and $\mathrm{NaNO}_{3}$ to $50 \mathrm{~mL}$ concentrated water sample to reach final concentration of $3 \% w / v$ and $2 \mathrm{M}$, respectively. Adjust the $\mathrm{pH}$ to 5.5 using $0.5 \mathrm{M} \mathrm{HCl}$.

10. Incubate at $50-90 \mathrm{rpm}$ on ice for $30 \mathrm{~min}$.

11. Centrifuge at $2500 \times g$ for $10 \mathrm{~min}$, then transfer the supernatant to a new tube. Discard pellet. Adjust the $\mathrm{pH}$ of the solution to 7.5 using $1 \mathrm{M} \mathrm{NaOH}$. 


\subsubsection{Virus Precipitation}

12. Add PEG 6000 and $\mathrm{NaCl}$ to reach final concentrations of $15 \%$ and $2 \% w / v$, respectively. Mix to dissolve PEG 6000 and incubate at $4{ }^{\circ} \mathrm{C}$ for $14-18 \mathrm{~h}$.

(1) PAUSE STEP The solution may be stored at $4{ }^{\circ} \mathrm{C}$ for up to 2 days.

13. Centrifuge at $10,000 \times \mathrm{g}$ for $30 \mathrm{~min}$ at $4{ }^{\circ} \mathrm{C}$. Discard supernatant.

14. Dissolve pellet in 1-4 mL PBS ( $\mathrm{pH}$ 7.4). The concentrate can be subjected to infectivity/integrity assays or nucleic acid extraction followed by real-time PCR quantification. Alternatively, viral nucleic acids can be extracted directly from the pellet.

OPTIONAL STEP To estimate method recovery percentile, RNA from $10 \mu \mathrm{L}$ mengovirus solution should be extracted and quantified.

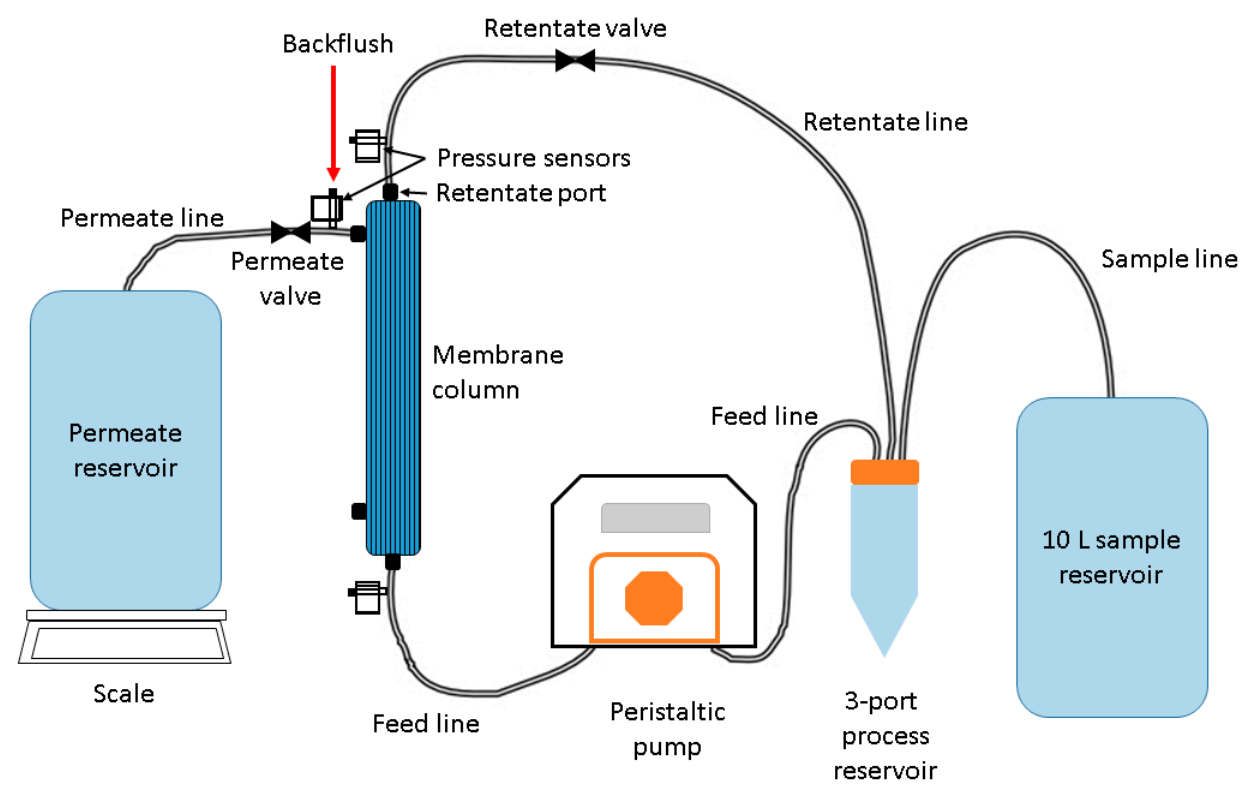

Figure 2. Schematic of tangential flow ultrafiltration setup.

\section{Expected Results}

For pilot validation, $2 \mathrm{~L}$ of deionized water was spiked with norovirus GII to reach final concentrations of $10^{6}, 10^{5}, 10^{4}, 10^{3}, 10^{2}$, and $10^{1}$ genome copies (gc)/L in duplicate. Samples were concentrated using the two-step concentration method. Viral RNA was extracted from the pellet (final volume: $50 \mu \mathrm{L}$ ) and quantified using qRT-PCR (sample volume: $2 \mu \mathrm{L}$ ) as described in Farkas et al. [10]. High recovery was observed in all norovirus concentrations (Table 1). The high deviations between replicates were a result of the limitations of the qPCR method used for quantification. The limit of quantification (LOQ) was $200 \mathrm{gc} / \mathrm{L}$ and the limit of detection (LOD) was approximately $50 \mathrm{gc} / \mathrm{L}$. LOD and LOQ can be further lowered by reducing the RNA eluent volume and increasing the sample volume in the qRT-PCR reaction.

Table 1. Norovirus recovery and standard deviation (SD) in deionized water using the two-step concentration method.

\begin{tabular}{cc}
\hline Norovirus Concentration $(\mathrm{gc} / \mathrm{L})$ & Recovery Percentile $(\mathrm{SD})$ \\
\hline $5.28 \times 10^{6}$ & $78(43)$ \\
$4.72 \times 10^{5}$ & $121(2)$ \\
$4.31 \times 10^{4}$ & $99(11)$ \\
$3.03 \times 10^{3}$ & $91(45)$ \\
$2.0 \times 10^{2}$ & $100(0)$ \\
\hline
\end{tabular}


For further validation, $10 \mathrm{~L}$ of surface water samples (river, estuarine, and sea) in triplicate were spiked with known concentrations of human enteric viruses (norovirus GII, sapovirus GI, hepatitis A virus, and human adenovirus type 40) and a mengovirus, which is often used as a process control for the extraction of enteric viruses from environmental matrices. The details of validation are described elsewhere [11]. Results showed that $10-100 \%$ recovery could be achieved in all sample types. In the same study, the usefulness of the method for wastewater samples was also investigated. Influent and effluent samples were taken in duplicate at four wastewater treatment plants. As the samples were expected to contain the target viruses, they were processed without spiking. High viral concentrations were observed, and the method showed great reproducibility. In subsequent samples spiked with mengovirus, at least $10 \%$ recovery was observed. No inhibition or cross-contamination between samples was observed. The method has also been successfully used for viral recovery from high volumes (50 L) of surface water for metagenomics applications [12].

\section{Applications and Recommendations}

The method described above is suitable for concentrating many different water samples and hence suitable for conducting viral surveillance, tracking contamination sources, and describing viral ecology. The TFUF method described here is suitable for viral recovery from the mPES MiniKros ${ }^{\circledR}$ hollow fiber filter (Spectrum Labs, Phoenix, AZ, USA); however, alternative recovery buffers may be used with different membranes. Furthermore, as the membrane used for the TFUF has a 100 kDa pore size, the method can potentially co-concentrate other microbes and protozoa as well, and hence the TFUF step of the concentration method enables accurate description of the microbial quality of a sample. In the current study, viral nucleic acids were directly extracted from the concentrated water samples; in addition, the concentrates are suitable for viral infectivity and capsid integrity assays as well [11]. For direct nucleic acid extraction, resuspension of the PEG precipitate is not necessary; nucleic acids can be extracted from the pellet. When PCR-based approaches are used for the quantification of viruses in the concentrate, the use of robust extraction and amplification methods is recommended, as organic matter that may interfere with the enzymes used for amplification are co-concentrated with viral particles. The addition of process control (e.g., mengovirus) to each sample to determine method efficiency is highly recommended.

Author Contributions: Conceptualization and Methodology, all; Validation, Investigation, K.F.; Writing-Original Draft Preparation, K.F.; Writing-Review and Editing, all; Funding Acquisition, D.J.

Funding: This work was funded by the Natural Environment Research Council (NERC) and the Food Standards Agency (FSA) under the Environmental Microbiology and Human Health (EMHH) Programme (NE/M010996/1).

Acknowledgments: The authors would like to thank Lindsay Smart (Spectrum Labs, UK) for his assistance in developing the method for water concentration.

Conflicts of Interest: The authors declare no conflict of interest.

\section{References}

1. Cashdollar, J.L.; Wymer, L. Methods for primary concentration of viruses from water samples: A review and meta-analysis of recent studies. J. Appl. Microbiol. 2013, 115, 1-11. [CrossRef] [PubMed]

2. Ikner, L.A.; Gerba, C.P.; Bright, K.R. Concentration and recovery of viruses from water: A comprehensive review. Food Environ. Virol. 2012, 4, 41-67. [CrossRef] [PubMed]

3. Soule, H.; Genoulaz, O.; Gratacap-Cavallier, B.; Chevallier, P.; Liu, J.-X.; Seigneurin, J.-M. Ultrafiltration and reverse transcription-polymerase chain reaction: An efficient process for poliovirus, rotavirus and hepatitis A virus detection in water. Water Res. 2000, 34, 1063-1067. [CrossRef]

4. Hill, V.R.; Polaczyk, A.L.; Hahn, D.; Narayanan, J.; Cromeans, T.L.; Roberts, J.M.; Amburgey, J.E. Development of a rapid method for simultaneous recovery of diverse microbes in drinking water by ultrafiltration with sodium polyphosphate and surfactants. Appl. Environ. Microbiol. 2005, 71, 6878-6884. [CrossRef] [PubMed] 
5. Holowecky, P.M.; James, R.R.; Lorch, D.P.; Straka, S.E.; Lindquist, H.D.A. Evaluation of ultrafiltration cartridges for a water sampling apparatus. J. Appl. Microbiol. 2009, 106, 738-747. [CrossRef] [PubMed]

6. Hill, V.R.; Kahler, A.M.; Jothikumar, N.; Johnson, T.B.; Hahn, D.; Cromeans, T.L. Multistate evaluation of an ultrafiltration-based procedure for simultaneous recovery of enteric microbes in 100-liter tap water samples. Appl. Environ. Microbiol. 2007, 73, 4218-4225. [CrossRef] [PubMed]

7. Rhodes, E.R.; Hamilton, D.W.; See, M.J.; Wymer, L. Evaluation of hollow-fiber ultrafiltration primary concentration of pathogens and secondary concentration of viruses from water. J. Virol. Methods 2011, 176, 38-45. [CrossRef] [PubMed]

8. Kahler, A.M.; Johnson, T.B.; Hahn, D.; Narayanan, J.; Derado, G.; Hill, V.R. Evaluation of an ultrafiltration-based procedure for simultaneous recovery of diverse microbes in source waters. Water 2015, 7, 1202-1216. [CrossRef] [PubMed]

9. Lewis, G.D.; Metcalf, T.G. Polyethylene glycol precipitation for recovery of pathogenic viruses, including hepatitis A virus and human rotavirus, from oyster, water, and sediment samples. Appl. Environ. Microbiol. 1988, 54, 1983-1988. [PubMed]

10. Farkas, K.; Hassard, F.; McDonald, J.E.; Malham, S.K.; Jones, D.L. Evaluation of molecular methods for the detection and quantification of pathogen-derived nucleic acids in sediment. Front. Microbiol. 2017, 8, 53. [CrossRef] [PubMed]

11. Farkas, K.; Cooper, D.M.; McDonald, J.E.; Malham, S.K.; de Rougemont, A.; Jones, D.L. Seasonal and spatial dynamics of enteric viruses in wastewater and in riverine and estuarine receiving waters. Sci. Total Environ. 2018, 634, 1174-1183. [CrossRef] [PubMed]

12. Adriaenssens, E.; Farkas, K.; Harrison, C.; Jones, D.; Allison, H.E.; McCarthy, A.J. Viromic analysis of wastewater input to a river catchment reveals a diverse assemblage of RNA viruses. mSystems 2018, 3, e00025-18. [CrossRef] [PubMed]

(C) 2018 by the authors. Licensee MDPI, Basel, Switzerland. This article is an open access article distributed under the terms and conditions of the Creative Commons Attribution (CC BY) license (http://creativecommons.org/licenses/by/4.0/). 